\title{
Gebelerde Sağlıklı Yaşam Davranışlarının ve Etkileyen Faktörlerin Belirlenmesi
}

\section{Determination of Healthy Life Behaviors and Affecting Factors in Pregnant Women}

\author{
${ }^{1}$ Handan ÖZCAN, ${ }^{2}$ Tuğçe POLAT, ${ }^{2}$ Mücahid YILMAZ, ${ }^{2}$ Arif ÖZTÜRK, ${ }^{2}$ Tolga AYDOĞAN \\ ${ }^{1}$ Sağlık Bilimleri Üniversitesi, Sağlık Bilimleri Fakültesi, Ebelik Bölümü, İstanbul, Türkiye \\ ${ }^{2}$ Gümüşhane Üniversitesi, Sağlık Bilimleri Fakültesi, Hemşirelik Bölümü, Gümüşhane, Türkiye
}

Handan Özcan: https://orcid.org/0000-0002-7131-1856

Tuğçe Polat: https://orcid.org/0000-0003-3017-934X

Mücahid Yilmaz: https://orcid.org/0000-0002-5727-8092

Arif Öztürk: https://orcid.org/0000-0003-2377-1206

Tolga Aydoğan: https://orcid.org/0000-0003-3202-3488

\section{ÖZ}

Amaç: Araştırma, gebelerde sağlıklı yaşam biçimi davranışlarını ve etkileyen faktörleri belirlemek amacıyla yapild1.

Materyal ve Metot: Tanımlayıcı ve kesitsel türde olan araştırmanın evrenini bir kamu hastanesinde, doğum polikliniklerine 30.02.2018-15.06.2018 tarihleri arasında başvuru yapan gebeler oluşturdu. Çalışmanın örneklemde çalışmaya dahil edilme kriterlerini sağlayan toplam 207 sağlıklı gebe ele alındı. Veri toplama aracı olarak kişisel bilgi formu ve Sağlıklı Yaşam Biçimi Davranışları Ölçeği kullanıld1.

Bulgular: Gebelerin yaş ortalaması $27,68 \pm 4,18$ (min:18, max:41)'dir. Gebelerin sağlık davranışları ölçeğinden almış oldukları en yüksek puan; manevi gelişim $(26,84 \pm 4,88)$, kişilerarası ilişkiler $(25,18 \pm 4,82)$ ve sağlık sorumluluğu $(24,49 \pm 4,40)$ olup, en düşük puan ise fiziksel aktiviteye $(14,99 \pm 4,71)$ aittir. Ev hanımı olan, düzenli egzersiz yapan, gündüzleri dinlenen, cinsel yaşamı değişmeyen, gebeliği planlı olan, bebeğinin doğum ağırlığ normal sınırlarında olan, son doğumunu vajinal yolla yapan kadınların sağlık davranışları puan ortalamaları daha yüksektir.

Sonuç: Gebelikte maternal ve fetal iyilik durumu için sağlıklı yaşam davranışları kaçınılmazdır. Multidisipliner bir ekiple gebeler için sağlıklı yaşam davranışlarına yönelik rehberlerin oluşturulması, farkındalıkların sağlanması önemlidir. Tespit edilen olumsuz sağlık davranışlarının gebe ile birlikte değerlendirilmesi ve değiştirilmesi yönünde destek sağlanması önerilmektedir.

Anahtar Kelimeler: Gebe, sağlık davranışı, yaşam biçimi

\section{ABSTRACT}

Objective: The research was carried out to determine healthy lifestyle behaviors and the influencing factors in pregnant women.

Materials and Methods: The universe of the research, which is descriptive and cross-sectional, was made up of pregnant women who applied to obstetrics clinics between 30.02.2018-15.06.2018. A total of 207 healthy pregnant women who met the inclusion criteria of the study in the sample were considered. Personal information form and Healthy Lifestyle Behaviors Scale were used as data collection tools.

Results: The average age of pregnant women is $27.68 \pm 4.18$. The highest score that pregnant women got from the health behavior scale; spiritual development (26.84 \pm 4.88$)$, interpersonal relationships (25.18 \pm 4.82$)$ and health responsibility $(24.49 \pm 4.40)$, and the lowest score belongs to physical activity $(14.99 \pm 4.71)$. Women who are housewives, exercise regularly, rest during the day, do not change their sex life, have a planned pregnancy, have a normal birth weight of their baby, have a final vaginal delivery, and have higher health behavior scores. Conclusions: Healthy lifestyle behaviors are inevitable for maternal and fetal well-being during pregnancy. It is important to create guides and awareness about healthy living behaviors for pregnant women. Support is provided to evaluate and change the negative health behaviors detected with the pregnant.

Keywords: Pregnant, health behavior, lifestyle

\footnotetext{
Sorumlu Yazar / Corresponding Author:

Handan Özcan

Dr. Öğretim Üyesi; Mekteb-i Tıbbiye-i Şahane, Selimiye mah.

Tibbiye Cad. No: 38, 34668 Üsküdar/ İstanbul, Turkey

Tel: :+90 2163463636

Fax: +902163463640

E-mail: hndnozcn@hotmail.com
}

Yayın Bilgisi / Article Info:

Gönderi Tarihi/ Received: 02/01//2020

Kabul Tarihi/ Accepted: 16/06/2020

Online Yayın Tarihi/ Published: 30/09/2020

*Atıf / Cited: Özcan H et al. Gebelerde sağlıklı yaşam davranışlarının ve etkileyen faktörlerin belirlenmesi. Online Türk Sağlık Bilimleri Dergisi 2020;5(3):482-492. doi: 10.26453/otjhs.669573

*Çalışma 26-28 Nisan 2018. 1. Uluslararası İstanbul Ebelik Günlerinde Sözel Bildiri (SS-093) olarak sunulmuştur. 


\section{GİRiş}

Sağlıklı bir toplum için kadının sağlıklı bir gebelik sürecini tamamlaması gerekmektedir. ${ }^{1}$ Gebelik, doğum ve doğum sonundaki sağlık davranışları, anne ve bebek sağlığının sürdürülmesindeki en önemli etkenlerdir. Gebelikte sağlıklı yaşam tarzını oluşturan bileşenler; uygun beslenme ve egzersiz, olumlu sağlık davranışları ve psikolojik sağlığın korunmasını içermektedir. ${ }^{2}$

Gebelikte annenin doğru beslenmesi fetal-maternal sağlık açısından çok önemlidir. Gebelikte yanlış beslenme ileriki zamanlarda çocuklarda birçok kronik hastalık görülme oranını artırmaktadır. ${ }^{3}$ Gebelikte beslenme yetersizliği ya da düşük kaliteli beslenmenin; doğum kusurları, serebral gelişimin bozulması, yarık dudak/yarık damak gibi anomaliler, preterm eylem, abortus, bozulmuş büyüme ve gelişme riskleri ile ilişkili olduğu belirtilmiştir. ${ }^{4}$ Haftada iki yada daha fazla sayıda balık tüketiminin erken doğum riskini azalttığ1, meyve ve sebzenin bolca tüketilmesinin preeklampsi gibi olumsuz sağlık sonuçlarının önlenmesinde etkili olduğu belirtilmiştir. ${ }^{5}$ Ayrıca gebelikte sağlıklı bir diyet, aşırı kilo alma olasılığını da azaltmaktadır. ${ }^{6}$

Gebelikte egzersiz, sağlıklı yaşam tarzının bir parçaS1 olarak tavsiye edilmektedir. ${ }^{7,8}$ Amerikan Kadın Doğum ve Jinekologlar Koleji, Kanada jinekolog ve Obstetrik Derneği gibi diğer birçok kuruluş gebelikte egzersizi önermektedir. Gebelere sağlıklı yaşam biçimi davranışları için haftada her gün ortalama 30 dakika veya daha fazla süre egzersiz yapmaları önerilmektedir. ${ }^{7-9}$ Yoğun egzersiz programları yerine 20 ile $30 \mathrm{dk}$ orta düzey aktiviteler (yürüme/tempolu yürüyüş, yüzme) önerilmektedir. ${ }^{10}$ Direnç ve güçlendirme egzersizlerinin gebelik üzerine etkilerinin değerlendirildiği bir çalışmada, bu egzersizlerin yenidoğanlar için herhangi bir sağlık riski taşımadığı ve gebe kadınların yaşam kalitelerini yükselttiği belirtilmiştir. Araştırmacılar egzersizin gebe kadının yaşamına tamamlayıcı bir unsur olarak eklenmesi gerektiğini, kadının bağımsız olarak yapabileceği egzersizler (direnç, güçlendirme, aerobik, dans, su egzersizleri, pelvik taban egzersizleri gibi) için desteklenmeleri ve gebelik boyunca egzersize devam edebilecekleri vurgulanmıştır. ${ }^{11}$

Gebelikte halsizlik ve yorgunluk yaygın olarak görülmektedir. Buna bağlı olarak huzursuzluk, gerginlik, korku, endişe, duygusallık ve uykusuzluk gelişebilir. Gebelikte vücudun ağırlık merkezi de değişmektedir. Bu sebeple kadın ayakta durabilmek için daha fazla efor harcar ve yorulur. Yorgunluğu azalt- mak için yapılacak işlerin, mümkün olduğunca oturarak yapılması önerilmektedir. Yine gebelere sigara, alkol ve toksik maddelerden uzak durmaları, kahve tüketimini azaltmak, cinsel yolla bulaşan enfeksiyonlardan korunmak, ilaç kullanımını düzenlenmek, diş bakımı yaptırmak gibi sağlık davranışlarının geliştirmesi ve sürdürmesi önerilmektedir. ${ }^{1}$ Gebenin sağlık davranışlarını gerçekleştirebilmesi için gebeliğinin planlı olması da önemli bir faktördür. Plansız gebeliklerde sigara dumanına maruz kalma, yüksek beden kitle indeksi, düşük folik asit takviyesi ve olumsuz doğum sonuçları ile kötü sağlık davranışları yüksek görülmektedir. ${ }^{12}$ Gebelikte ve erken dönemde çoklu sağlık davranış değişikliği ile anne-çocuk sağlığını en üst düzeye çıkarmak, maliyet ve zaman açısından verimli ve etkili bir araç olduğu belirtilmiştir. ${ }^{13}$ Araştırma, gebelerde sağlıklı yaşam biçimi davranışlarını ve etkileyen faktörleri belirlemek amacıyla planlandi.

\section{MATERYAL VE METOT}

Araştırmanın Tipi ve Etik: Tanımlayıcı ve kesitsel özellikte olan bir çalışmadır. Çalışmanın yürütülebilmesi için kurum ve etik kurul izinleri alınmıştır. Etik kurul izni Gümüşhane Üniversitesi Bilimsel Araştırma ve Yayın Etiği Kurulu'ndan alınmıştır (Tarih: 16.02.2018, karar no: 95674917-604.01.02E.6100).

Araştırmanın Evreni ve Örneklemi: Araştırmanın evrenini bir kamu hastanesi kadın doğum polikliniklerine başvuru yapan gebeler oluşturmaktadır. Örneklemini ise 30.02.2018/15.06.2018 tarihleri arasında polikliniklere başvuru yapan ve dahil edilme kriterlerini sağlayan toplam 207 gebe oluşturmaktadır. Örneklem hacminin yeterliliği için referans makale olarak Onat ve Aba tarafindan 255 gebe ile gerçekleştirilen "Gebelerde sağlıklı yaşam biçimi davranışları ve ilişkili faktörler" başlıklı araştırmadan yararlanılmıştır. ${ }^{14} \mathrm{Bu}$ araştırma için PASS-11 programı kullanılarak yapılan güç analizinde 207 kişi ile çalışıldığında da Power'in 1'e yakın olduğu görülmüş ve veri toplamaya son verilmiştir Dahil edilme kriterlerini ise belirtilen tarihlerde ulaşılan, çalışmaya gönüllü olarak katılmayı kabul eden, Türkçe konuşabilen ve riskli gebelik öyküsü olmayan gebeler sağlamaktadır. Verilerin rahat ve güvenli bir şekilde toplanabilmesi için önceden belirlenen uygun bir poliklinikte gebeler ile görüşülmüştür. Gebelere çalışmanın amacı anlatılmış, çalışmaya katılmak isteyenlerden sözel onam alınmış ve veriler toplanmıştır. Şu anki gebeliğinde herhangi bir risk durumu 
olan gebeler çalışmaya dahil edilmemiştir. Bir gebe ile yaklaşık $20 \mathrm{dk}$ görüşülmüştür.

Veri Toplama Araçları: Veri toplama aracı; Kişisel bilgi formu ve Sağlıklı Yaşam Biçimi Davranışları Ölçeği olmak üzere iki aşamadan oluşmaktadır.

1. Kişisel bilgi formu: Form gebelerin sosyodemografik özellikleri ile obstetrik öyküleri ve gebelik dönemindeki sağlık davranışlarını sorgulayan toplam 47 sorudan oluşmaktadır

2. Sağlıklı Yaşam Biçimi Davranışları Ölçeği II (SYBDÖ): Ölçek bireyin sağlıklı yaşam biçimi ile ilişkili olarak geliştirilen sağlık davranışlarını ölçmektedir. Bahar ve arkadaşları tarafindan 2008 y1lında Türkçeye uyarlanmıştır. ${ }^{15}$ Ölçek toplam puan üzerinden değerlendirilmektedir, maksimum 208, minimum 52 puan alınmaktadır. Ölçeğin 6 tane alt boyutu (Sağlık sorumluluğu, Fiziksel Aktivite, Beslenme, Manevi Gelişim, Kişilerarası İlişkiler, Stres Yönetimi) vardır. Ölçeğin Alpha güvenirlik katsayısı 0,94 olup, alt boyutların Alpha güvenirlik katsayı değerleri 0,79-0,87 arasında değişmektedir. Yapılan çalışmada Sağlıklı Yaşam Biçimi Davranışları Ölçeğinin, Cronbach Alfa güvenirlik katsayısı 0,82'dir.

Verilerin Analizi ve Yorumu: Araştırma sonucu elde edilen veriler SPSS-22 programı ile değerlendirilmiş hata kontrolleri, tabloları ve istatistiksel analizleri yapılmıştır. İstatistiksel değerlendirmelerde sayı ve yüzde, değerleri verilmiştir. Normallik analizleri öncesinde kayıp veri, uç değer ayıklamaları yapılmıştır. Sonrasında normal dağılıma uygunluk için histogram çizimleri yapılmış, skewness ve kurtosis değerlerine bakılmış ayrıca KolmogorovSmirnov analizleri yapılmıştır. Tüm basamaklar sonrasında normal dağılım göstermeyen SYBDÖ'ne logaritmik dönüşümler uygulanmış ancak yine normal dağılım koşullarının oluşmadığı tespit edilmiştir. $\mathrm{Bu}$ nedenle sağlıklı yaşam biçimi davranışları üzerinde bağımsız değişkenlerin fark oluşturup oluşturmadığını belirlemek için, Mann Whitney U (U) testi yapılmıştır. $\mathrm{p}<0.05$ istatistiksel anlamlılık düzeyi olarak kabul edilmiştir.

\section{BULGULAR}

Gebelerin yaş ortalaması 27,68 $\pm 4,19$ (min:18, max:41), eşlerinin yaş ortalaması $31,14 \pm 4,90$ (min:19, max:49), evlilik yıl ortalamas1 5,02 $\pm 4,41$ (min:1, max:22)'dir. BKI ortalamas1 26,06 $\pm 4,57$ (min:22, max:34)'dir. Gebelerin bazı sosyodemografik özellikleri Tablo 1'de verildi.

Gebelerin \%16,5'i eşi ile akrabadır, \%7'sinin sürekli kullandığı bir ilaç vardır ve \%6,5'i sigara kullanmaktadır. \%48'inin ilk gebeliğidir, \%4'ünün ölü doğumu veya yenidoğan kaybı, \%13'ünün düşük öyküsü vardır. Gebelerin \%10,5'inin son gebeliğindeki bebeğinin doğum ağırlığı 2500 gramın altında, $\% 5$ 'inin son gebeliğindeki bebeğinin doğum ağırlığı 4000 gr üzerindedir ve \%68,4'ünün son doğum şekli vajinal doğumdur. Araştırmada kadınların gebelikleri ile ilgili bazı durumları Tablo 2'de ele alındı.

Gebelerin \%10,5'i gebelik döneminde herhangi bir alternatif yöntem (\%9'u bitkisel tedavi, \%0,5'i yoga) kullanmaktadır. \%6'sı sağlık personeli tavsiyesi ile kullanmıştır. Gebelerin \%52,8'inin cinsel hayatında azalma olduğu, \%2'sinin psikiyatrik bir tanı aldığ 1 belirlendi. Gebelerin SYBDÖ almış oldukları puan ortalamaları Tablo 3 'te verildi.

Gebelerin SYBDÖ almış oldukları en yüksek puanlar manevi gelişim, kişilerarası ilişkiler ve sağlık sorumluluğu olup, en düşük puan ise fiziksel aktivitedir. Gebelerde SYBDÖ puanın bazı değişkenlerle karşılaştırılması Tablo 4'te verildi.

Ev hanımı olan, düzenli egzersiz yapan, gündüzleri dinlenen, cinsel yaşamı değişmeyen, gebeliği planlı olan, bebeğinin doğum ağrılığı normal sınırlarında olan (2,5-4 kg aras1), son doğumunu vajinal yolla yapan kadınlar arasında SYBD toplam puanları daha yüksek olup arada istatistiksel olarak anlamlı farklar belirlendi.

\section{TARTIŞMA VE SONUÇ}

Çalışmada gebelerin yaş ortalaması 27,68 olup, yaklaşık yarısının eğitim seviyesi üniversite düzeyindedir. Çalışmada kadınların hemen hemen hepsinin (\% 97,6) gebelik süreci hakkında bilgisi vardır. Gebelerin $\% 88,4$ 'ü ise bilgileri sağlık personelinden almıştır. Bu durum bize kadınların eğitim seviyelerinin yüksek olması ve yaş ortalamalarının düşük olmasindan kaynaklanabileceğini göstermektedir.

$\mathrm{Bu}$ çalışmada kadınların yaklaşık dörtte birinin (\% 76,4) gebeliği planlıdır. Gebeliği planlı olanlarda beslenme, stres yönetimi ve genel SYBD daha iyidir. Yapılan çalışmalarda planlı gebeliklerin sağlıklı yaşam biçimi davranışları ile hamilelik sonuçlarını etkilediği belirtilmiştir. Planlı gebeliklerde, prenatal bakım alma, gebe kalmadan önce folik asit kullanım1, alkol, sigara gibi maddelerin birakılması, beslenmeye dikkat etme gibi birçok sağlık davranışı gelişmekte ve gebelik boyunca sürdürülmektedir. ${ }^{16,17}$ Çalışma sonuçları literatürle benzerlik göstermekte ve planlı olan gebeliklerde sağlık davranışlarının daha yüksek olduğu belirlenmiştir.

Gebelerin SYBDÖ almış oldukları en yüksek puanlar manevi gelişim, kişilerarası ilişskiler ve sağlık sorumluluğuna aittir. Bu durum bize gebelikte yaşa- 
nılan psikolojik değişiklikler, gebeliğin planlanmış olması, gebelerin sürekli sağlık kontrollerine gitmelerinden ve yaklaşık yarısının ilk gebeliği olmasından kaynaklanabileceğini düşündürmektedir. Sağlık11 bir gebelik süreci için sağlık sorumluluğu önemli olan bir etmendir. Auerbach ve ark yaptıkları çalışmada, gebelikteki sağlık kontrollerinin anne ve bebek sağlığını direk etkilediği belirtilmiştir. ${ }^{18}$ Manevi gelişim ve sağlık sorumluluğu özellikle sağlık davranışlarının kazanılması için önemli bir etkenlerdir. Gebenin beslenmesinin düzenlenmesi, vitamin takviyesi, sigara, alkol, kahve gibi zararlı maddelerden uzak durması, stres yönetimi gibi davranışların geliştirilmesi, sağlık risklerini azalmaktadır. Çalışmalarda sağlık kontrollerinin düzenli yapılması ile yaşam tarzı değişikliği ve sağlığı teşvik edici davranışlar arasında ilişki olduğu belirtilmiştir. Örneğin kontrollere giden gebelerde sigarayı bırakma, kahve tüketmeme, doğum sınıflarına katılma ve ağrı kontrol tekniklerini öğrenme durumlarının daha yüksek olduğu saptanmıştır. ${ }^{19-21}$

Gebelik ve doğum, fetal büyüme ve gelişim için kadının vücudunda, tüm organ ve sistemlerde değişikliklerin meydana geldiği bir süreçtir. Meydana gelen bu fizyolojik değişiklikler sonucunda da bazen komplikasyon riskleri artmaktadır. ${ }^{22}$ Literatürdeki fikir birliğine göre gebelikte orta düzey egzersiz; komplikasyon risklerini azaltmada ve hem anne hemde bebek sağlığı için önerilmektedir. Gebelikte yapılan egzersiz, gestasyonel diyabetin önlemesi, psikolojik iyilik halinin sürdürülmesi, fetüse giden kan akımının artması ve oksijenasyonun sağlaması gibi birçok yararı bulunmaktadır. ${ }^{23,24}$ Çalışmamızda gebelerin SYBDÖ almış oldukları en düşük puan fiziksel aktivitedir. Kadınların sadece \%24,2'si düzenli egzersiz yapmaktadır. Çalışmamızdaki gebe kadınlar arasında fiziksel aktivitenin düşük olmasına; gebelikte egzersiz yapmanın sakıncalı olmasını düşünmek, önceden düşük ve riskli gebelik öykülerinin olması gibi faktörlerin sebep olduğu düşünülmektedir. Kadının gebelikten önceki fiziksel egzersiz durumu, gebelikteki davranışlarını da etkilemektedir. Çalışmamızda düzenli egzersiz yapan gebelerde ise sağlık sorumluluğu, fiziksel aktivite, beslenme, manevi gelişim, kişilerarası ilişkiler ve stres yönetimi daha yüksektir.

Çalışmaya katılan gebelerin \%38,4'ü çalışmakta ve $\% 66,2$ 'si gün içinde yeterince dinlenmektedir. Gebelerde SYBD etkileyen değişkenlerin incelenmesi sonucunda; çalışan gebe kadınlar arasında stres yönetiminin daha düşük olduğu belirlendi. Ev hanımlı olan gebelerin sağlık davranışları toplam puanı daha yüksektir. Bunun yanında gündüzleri evde dinlenme imkânı olan gebelerin beslenme, manevi gelişim ve stres yönetimlerinin daha iyi olduğu saptandı. Katz ve ark yaptıkları araştırmada, çalışan gebe kadınların; çevresel stres, çalışma şartları, psikolojik stres ve sosyo-ekonomik durum gibi faktörlere daha fazla maruz kaldıkları belirtilmiştir. Zamanla bu stresörler de hipertansiyon, gebelik diyabeti gibi komplikasyonlara yol açmaktadırlar. Stresörlerin muayene sırasında sorgulanması, fetal maternal sağlık üzerindeki etkilerinin belirlenmesi gerekmektedir. Araştırmada iş kaynaklı stresörlere karşı; iş yoğunluğunun azaltılması ya da işin bırakılması gibi öneriler sunulmuştur. ${ }^{25}$ Ayrica gebelikte meydana gelen fizyolojik ve psikolojik değişiklikler de gebenin stresle başa çıkma yeteneğini düşürmektedir. Stres gebelerde; endişe, gerginlik, yorgunluk, uyku problemleri gibi negatif duygulara ve fiziksel tepkilere sebep olmaktadır. Gebelikte stres yönetimi için; strese sebep olan faktörlerin belirlenmesi, stresi azaltmak için alternatif stratejiler geliştirilmesi ve stresle başa çıkma eğitimlerin planlanması önerilmektedir. ${ }^{26}$ Stresten uzak olan, dinlenme imkânı bulunan gebelerin sağlık davranışları daha iyidir. Kadınlara sağlıklı bir gebelik süreci için stresten uzak durmaları, gün içerisinde belirli aralıklarla dinlenmeleri, çevrelerindeki stresörlerin azaltılması ya da uzak durmaları gerektiği önerilebilir.

Çalışmada cinsel yaşamının etkilendiği belirtilen gebelerin diğerlerine göre sağllk sorumluluğu ve stres yönetimi puanları istatistiksel olarak daha düşük bulundu. Literatürde cinsellik ve gebelik sürecini, kadının zihinsel durumunun etkilediği belirtilmiştir. Gebelikte yaşanılan endişe düzeyi cinsel aktivite kalitesini azaltmaktadır. Özellikle düşük, erken doğum tehdidi, bebek sağlığının etkilenmesi gibi düşünceler, gebelerde cinsel aktiviteyi azaltmaktadır. Yapılan çalışmada gebelikte yaşanılan cinsel aktivite sorunlarında, sağlık personelinin cinsel aktivite problemlerine yönelik danışmanlık rollerinin yetersiz olduğu vurgulanmıştır. ${ }^{27,28}$ Gebelik döneminde cinsel problemlerin sorgulanıp, gerekli danışmanlıkların yapılması, sağlıklı cinsel aktivitenin sürdürülmesi önerilmektedir.

Günlük işlerinde yardım alan gebelerde, manevi gelişim ve stres yönetimi; son doğumunda bebeğinin ağırlığı 2,500 gr altında olan gebelerde sağlık sorumluluğu, fiziksel aktivite, manevi gelişim ve kişilerarası ilişkileri daha düşüktür. Son doğumunda bebeğinin ağırlığı 4000 gr üzerinde olan gebelerde ise sağlık sorumluluğu ve stres yönetimi daha yüksektir. Son doğum şekli vajinal yolla olanlarda ise 
sağlık sorumluluğu, beslenme ve stres yönetimi daha iyidir. Yapılan çalışmalarda özgüveni ve kişilerarası ilişkileri iyi olan gebeler arasında doğum sonuçlarının daha iyi olduğu belirtilmiştir. Kişilerarası ilişkileri, manevi gelişimi ve stres yönetimi iyi olan gebelerin bebeklerinin de doğum ağırlıkları ve sağlık durumlarının daha iyi olduğu bildirilmiştir. Hamileliğin getirdiği fizyolojik değişikliklere rağmen sağlıklı bir bebek için gebelerin uygulamış oldukları sağlık davranışlarına adaptasyonları ve uyumları çok önemlidir. ${ }^{18,29}$

Araştırmada çalışmayan, düzenli egzersiz yapan, gündüzleri gün içinde dinlenme firsatı olan ve ev işlerinde yardım alan, cinsel yaşamı değişmeyen, gebeliği planlı olan, son doğumu vajinal yolla ve bebeğinin doğum ağırlığı normal sinırlarda olan, gebeliğinde enfeksiyon geçirmeyen gebelerde SYBD daha yüksektir.

Gebelikte maternal ve fetal iyilik durumu için sağlıklı yaşam davranışları kaçınılmazdır. Multidisipliner bir ekiple gebeler için sağlıklı yaşam davranışlarına yönelik rehberlerin oluşturulması, farkındalıkların sağlanması önemlidir. Tespit edilen olumsuz sağlık davranışlarının gebe ile birlikte değerlendirilmesi ve değiştirilmesi yönünde destek sağlanması önerilmektedir. Gebelik sürecinin sağlıklı bir şekilde sürdürülmesi için kadınlara gebe kalmadan önce ve gebelik boyunca, sağlık davranışlarını geliştirmek için rehberlik yapılmalıdır. Kilolu kadınların kilo vermesi, sağlıklı beslenmenin sürdürülmesi, stres yönetimi, fiziksel egzersizin planlaması, cinsel aktivitenin sürdürülmesi, çalışma şartlarının ayarlanması gibi rehberlik hizmetlerinin sunulması çok önemlidir. Bunun yanında alışkanlıklarının da değerlendirilmesi gerekmektedir. Sigara, alkol, kahve tüketimi, beslenme koşulları, kronik hastalıkların ve kullanılan ilaçların düzenlenmesi gibi planlamaların yapılması gerekmektedir. Geçmişteki davranışların değiştirilmesi ve yeni davranışlara uyum sağlanılması konusunda danışmanlık yapılması, süreç yönetimi hakkında bilgi verilmesi ve gebelere destek sağlanması önerilmektedir.

Etik Komite Onayı: Çalışmamız Gümüşhane Üniversitesi Bilimsel Araştırma ve Yayın Etiği Kurulu tarafindan onaylandı (Tarih: 16.02.2018, karar no: 95674917-604.01.02-E.6100).

Çıkar Çatışması: Yazarlar çıkar çatışması bildirmemişlerdir.

Yazar Katkılart: Fikir - HÖ, TP, MY, AÖ, TA; Denetleme - HÖ; Malzemeler - HÖ, TP, MY, AÖ,
TA; Veri toplanması ve işlemesi - TP, MY, AÖ, TA; Analiz ve/veya yorum - HÖ; Yazıyı yazan - HÖ.

Hakem Değerlendirmesi: Dış bağımsız.

\section{KAYNAKLAR}

1. Er S. Gebelikte sağlık uygulamaları ölçeği Türkçe formunun geçerlik ve güvenirlik çalışması. Yüksek Lisans Tezi, Ege Üniversitesi, İzmir, 2006.

2. Davis AM, Wambach KA, Nelson EL, et al. Health behavior change in pregnant women: A two-phase study. Telemedicine and e-Health. 2014;20(12):1-5.

3. Hyde NK, Brennan-Olsen SL, Bennett K, Moloney DJ, Pasco JA. Maternal nutrition during pregnancy: Intake of nutrients important for bone health. Matern Child Health. J 2017;21 (4):845-851.

4. Haider BA, Olofin I, Wang M, et al. Anaemia, prenatal iron use, and risk of adverse pregnancy outcomes: systematic review and meta-analysis. Br Med J. 2013;21:3433.

5. Meltzer HM, Branstaeter AL, Nilsen RM, Magnus P, Alexander J, Haugen M. Effect of dietary factors in pregnancy on risk of pregnancy complications: results from the Norwegian Mother and Child Cohort study. Am J Clin Nutr. 2011;94:1970-1974.

6. Wilkinson SA, Walker A, Tolcher D. Reevaluation of women's nutritional needs, knowledge and behaviours in a tertiary maternity service: are we meeting women's needs yet? Nutr Diet. 2013;70:181-187.

7. Morris SN, Johnson NR. Exercise during pregnancy: acritical appraisal of the literature. J Reprod Med. 2005;50:181-188.

8. Davies GA, Wolfe LA, Mottola MF, MacKinnon C. Joint SOGC/CSEP clinical practice guideline: exercise in pregnancy and the postpartum period. Can J Appl Physiol. 2003;28:330-341.

9. Artal R, O'Toole M, White S. Guidelines of the ACOG for exercise during pregnancy and the Postpartum period. Br J Sports Med. 2003;37:612.

10. Amezcua-Prieto C, Olmedo-Requena R, Jimenez -Mejias E, et al. Changes in leisure time physical activity during pregnancy compared to the prior year. Matern Child Health J. 2013;17:632-638.

11. Barakat R, Perales M. Resistance Exercise in Pregnancy and Outcome. Clinical Obstetrics and Gynecology. 2016;59(3):591-599. 
12. Cheng ST, Loy SL, Cheung TB, et al. Demographic characteristics, health behaviors before and during pregnancy, and pregnancy and birth outcomes in mothers with different pregnancy planning status. Department Prev Sci. 2016;17 (8):960-969.

13. Prochaska JJ, Spring B, Nigg CR. Multiple health behavior change research: An introduction and overview. Prev Med. 2008;46:181-188.

14. Onat G, Aba YA. Health-promoting lifestyles and related factors among pregnant women. Turk J Public Health. 2014;12(2):69-79.

15. Bahar Z, Beşer A, Gördes N, Ersin F, Kıssal A. Sağlıklı Yaşam Biçimi Davranışları-2'nin geçerlik ve güvenilirlik çalışması. Cumhuriyet Üniversitesi Hemşirelik Yüksekokulu Dergisi. 2008;12 (1):1-13.

16. Carson C, Redshaw M, Sacker A, Kelly Y, Kurinczuk JJ, Quigley MA. Effects of pregnancy planning, fertility, and assisted reproductive treatment on child behavioral problems at 5 and 7 years: evidence from the Millennium Cohort Study. Fertil Steril. 2013;99:456-463.

17. Stern J, Salih Joelsson L, Tyden T, et al. Is pregnancy planning associated with background characteristics and pregnancy-planning behavior? Acta Obstet Gynecol Scand. 2016;95:182-189.

18. Auerbach MV, Lobel M, Cannella DT. Psychosocial correlates of health-promoting and healthimpairing behaviors in pregnancyJ Psychosom Obstet Gynaecol. 2014;35(3):76-83.

19. Cannella D, Auerbach M, Lobel M. Predicting birth outcomes: together, mother and health care provider know best. J Psychosom Res. 2013;75:299-304.

20. Haslam C, Lawrence W. Health-related behavior and beliefs of pregnant smokers. Health Psychol. 2004;2:486-491.

21. Weisman CS, Hillemeier MM, Chase GA, et al. Women's perceived control of their birth outcomes in the central Pennsylvania women's health study: Implications for the use of preconception care. Womens Health Issues. 2008;18:17 -25 .

22. Barakat R, Perales M, Bacchi M, Coteron J, Refoyo I. A program of exercise throughout pregnancy. Is it safe to mother and newborn? Am J Health Promot. 2014;29:2-8.

23. de Barros MC, Lopes MA, Francisco RP, Sapienza $\mathrm{AD}$, Zugaib $\mathrm{M}$. Resistance exercise and glycemic control in women with gestational diabetes mellitus. Am J Obstet Gynecol. 2010;203(6):551-556.
24.Perales M, Refoyo I, Coteron J, Bacchi M, Barakat R. Exercise during pregnancy attenuates prenatal depression: A randomized controlled trial. Eval Health Prof. 2015;38:59-72.

25. Katz VL. Work and work related stress in pregnancy. Clinical Obstetrics And Gynecology. 2012;55(3):165-173.

26. Jallo N, Salyer J, Ruiz RJ, French E. Perceptions of guided 1magery for stress management in pregnant African American women. Arch Psychiatr Nurs. 2015;29(4):249-254.

27. Gałązka I, Drosdzol-Cop AB， Naworska B, Czajkowska M, Skrzypulec-Plinta V. Does anxiety modify sexuality of pregnant women? Ginekol Pol. 2017;88(12):662-669.

28. Staruch M, Kucharczyk A， Zawadzka K, Wielgos M, Szymusik I. Sexual activity during pregnancy. Neuro Endocrinol Lett. 2016;37 (1):53-58.

29. Rasmussen HN, Scheier MF, Greenhouse JB. Optimism and physical health: a meta-analytic review. Ann Behav Med. 2009;37:239-256. 
Tablo 1. Gebeler in bazı sosyo-demografik özellikleri.

\begin{tabular}{|l|c|c|l|c|c|}
\hline Öğrenim durumu & $\mathbf{n}$ & $\mathbf{\%}$ & Eşin öğretim durumu & $\mathbf{n}$ & $\mathbf{\%}$ \\
\hline İlkokul mezunu & 18 & 8,7 & İlkokul mezunu & 10 & 4,8 \\
\hline Ortaöğretim mezunu & 34 & 16,4 & Ortaöğretim mezunu & 13 & 6,3 \\
\hline Lise mezunu & 54 & 26,1 & Lise mezunu & 64 & 31,1 \\
\hline Üniversite mezunu & 101 & 48,8 & Üniversite mezunu & 119 & 57,8 \\
\hline Toplam & 207 & 100,0 & Toplam & 207 & 100,0 \\
\hline Meslek durumu & $\mathbf{n}$ & $\mathbf{\%}$ & Eşin meslek durumu & $\mathbf{n}$ & $\mathbf{\%}$ \\
\hline Ev hanım1 & 126 & 61,8 & Ĕ̆itim ve sağlık personeli & 48 & 23,4 \\
\hline Çalışıor & 78 & 38,2 & Memur & 62 & 30,2 \\
\hline Toplam & 204 & 100,0 & İşçi & 91 & 44,4 \\
\hline & & & Çalışmıyor & 4 & 2,0 \\
\hline & & & Toplam & 205 & 100,0 \\
\hline Gelir durumu & $\mathbf{n}$ & $\mathbf{\%}$ & Yaşanılan yer & $\mathbf{n}$ & $\mathbf{\%}$ \\
\hline Gelir giderden az & 11 & 5,4 & Köy & 14 & 6,8 \\
\hline Gelir gidere eşit & 151 & 73,7 & İlçe & 156 & 17,6 \\
\hline Gelir giderden fazla & 43 & 21,0 & İl & 205 & 100,0 \\
\hline Toplam & 205 & 100,0 & Toplam & & \\
\hline
\end{tabular}


Tablo 2. Katılımcıların gebelikleri ile ilgili bazı durumları.

\begin{tabular}{|l|c|c|l|c|c|}
\hline $\begin{array}{l}\text { Gebelik süreci hakkında bilgi } \\
\text { durumu }\end{array}$ & $\mathbf{n}$ & $\mathbf{\%}$ & Gebeliğin plan durumu & $\mathbf{n}$ & $\mathbf{\%}$ \\
\hline Hayır & 5 & 2,4 & Evet & 156 & 76,8 \\
\hline Evet & 201 & 97,6 & Hayır & 47 & 23,2 \\
\hline Toplam & 206 & 100,0 & Toplam & 203 & 100,0 \\
\hline $\begin{array}{l}\text { *Bilgi kaynağı (Birden fazla yanıt } \\
\text { verilmiştir) }\end{array}$ & $\mathbf{n}$ & $\mathbf{\%}$ & $\begin{array}{l}\text { Gebelik için ilaç kullan- } \\
\text { ma durumu }\end{array}$ & $\mathbf{n}$ & $\mathbf{\%}$ \\
\hline Aile/akraba & 41 & 19,8 & Hayır & 17 & 8,2 \\
\hline Sağlı çalışanları & 183 & 88,4 & Evet & 190 & 91,8 \\
\hline Komşu/arkadaş & 32 & 15,5 & Toplam & 207 & 100,0 \\
\hline Diğer gebeler & 25 & 12,1 & & & \\
\hline Sosyal medya & 34 & 16,4 & & & \\
\hline $\begin{array}{l}\text { Şu anki gebelikte enfeksiyon ge- } \\
\text { çirme durumu }\end{array}$ & $\mathbf{n}$ & $\mathbf{\%}$ & Gün içinde yeterince din- \\
\hline Hayır & 182 & 87,9 & Hayır & $\mathbf{n}$ & $\mathbf{\%}$ \\
\hline Evet & 21 & 10,1 & Evet & 70 & 33,8 \\
\hline Toplam & 203 & 100,0 & Toplam & 207 & 66,2 \\
\hline İşlerde birinin yardımcı olması & $\mathbf{n}$ & $\mathbf{\%}$ & Düzenli egzersiz yapma & $\mathbf{n}$ & $\mathbf{\%}$ \\
\hline Hayır & 105 & 51,0 & Hayır & 157 & 75,8 \\
\hline Evet & 101 & 49,0 & Evet & 50 & 24,2 \\
\hline Toplam & 206 & 100,0 & Toplam & 207 & 100,0 \\
\hline
\end{tabular}


Tablo 3. Gebelerin Sağlıklı Yaşam Biçimi Davranışları Ölçeği’nden almış oldukları puan ortalamaları.

\begin{tabular}{|l|c|c|c|c|}
\hline SYBDÖ Alt Boyutu & n & ort $\pm \mathbf{s s}$ & min & max \\
\hline Sağlık sorumluluğu & 207 & $24,49 \pm 4,40$ & 12 & 34 \\
\hline Fiziksel Aktivite & 207 & $14,99 \pm 4,71$ & 8 & 31 \\
\hline Beslenme & 207 & $22,85 \pm 4,45$ & 12 & 37 \\
\hline Manevi Gelişim & 207 & $26,84 \pm 4,88$ & 14 & 36 \\
\hline Kişilerarası İlişkiler & 207 & $25,18 \pm 4,82$ & 14 & 36 \\
\hline Stres Yönetimi & 207 & $20,69 \pm 4,75$ & 10 & 38 \\
\hline Toplam & 207 & $134,80 \pm 21,37$ & 84 & 203 \\
\hline
\end{tabular}

SYBDÖ: Sağlıklı Yaşam Biçimi Davranışları Ölçeği 

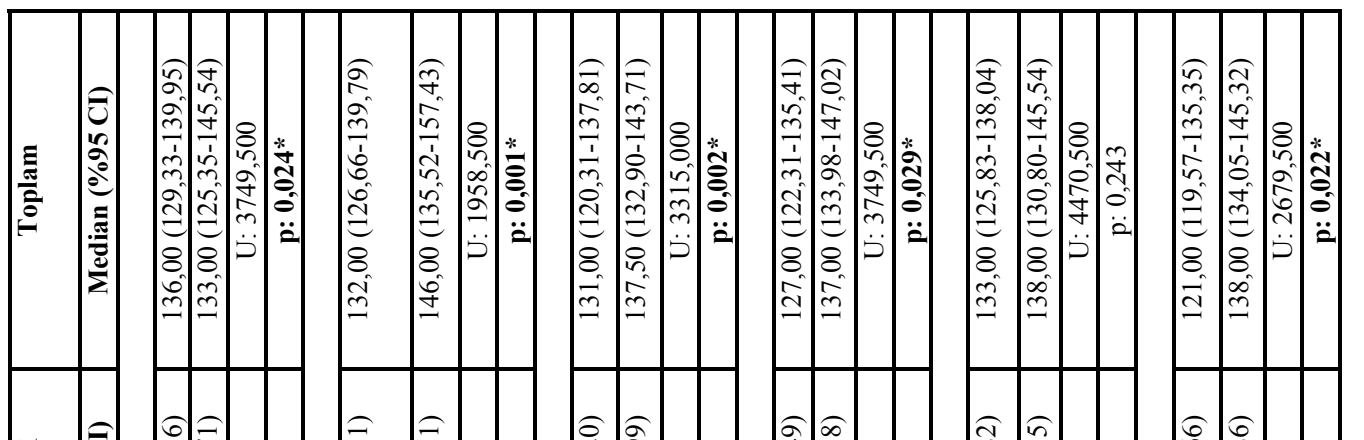

- $6=$

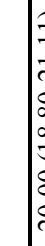



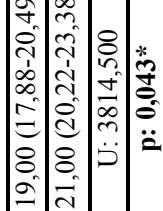

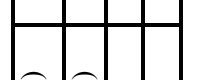
$\bar{\Xi}$

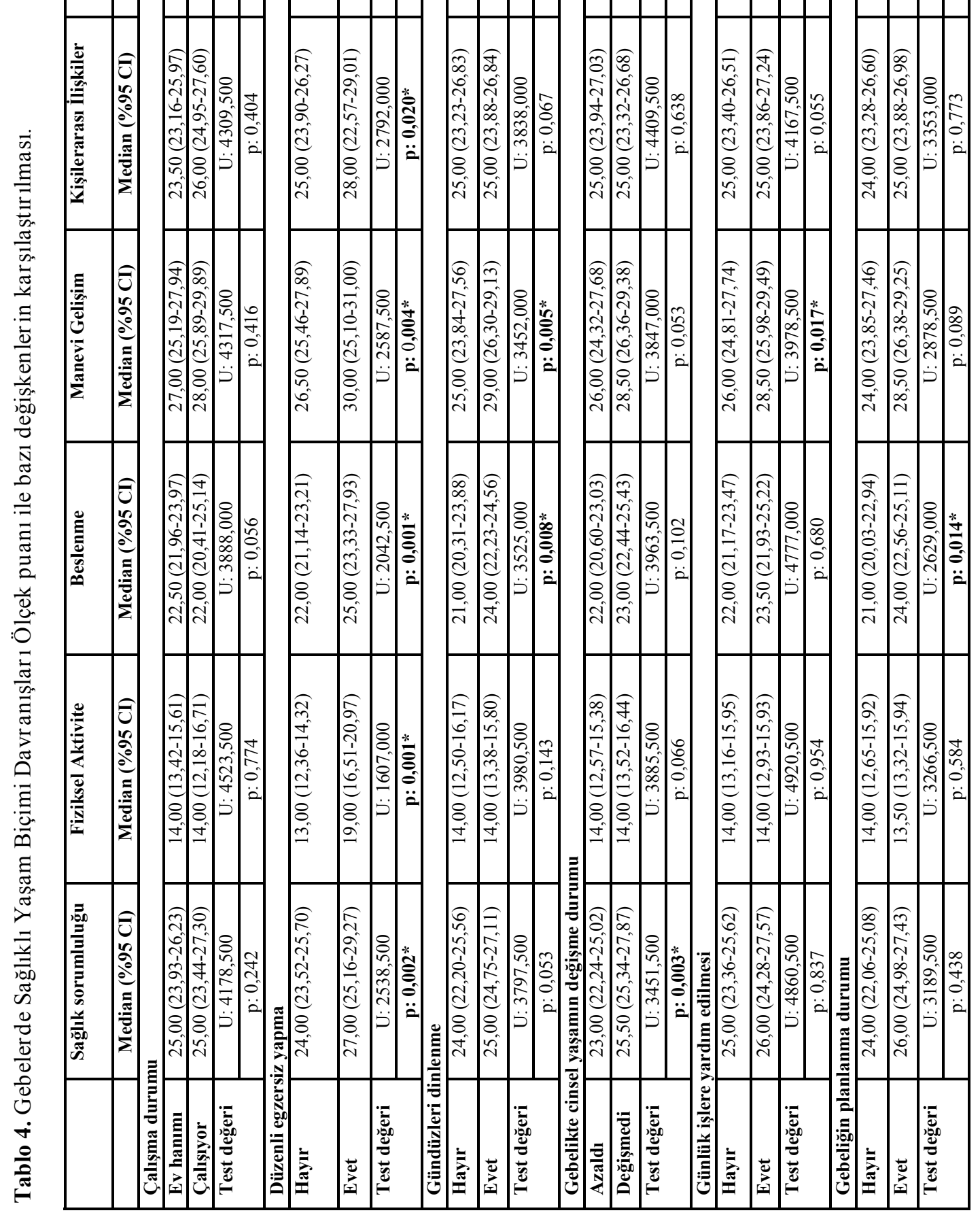




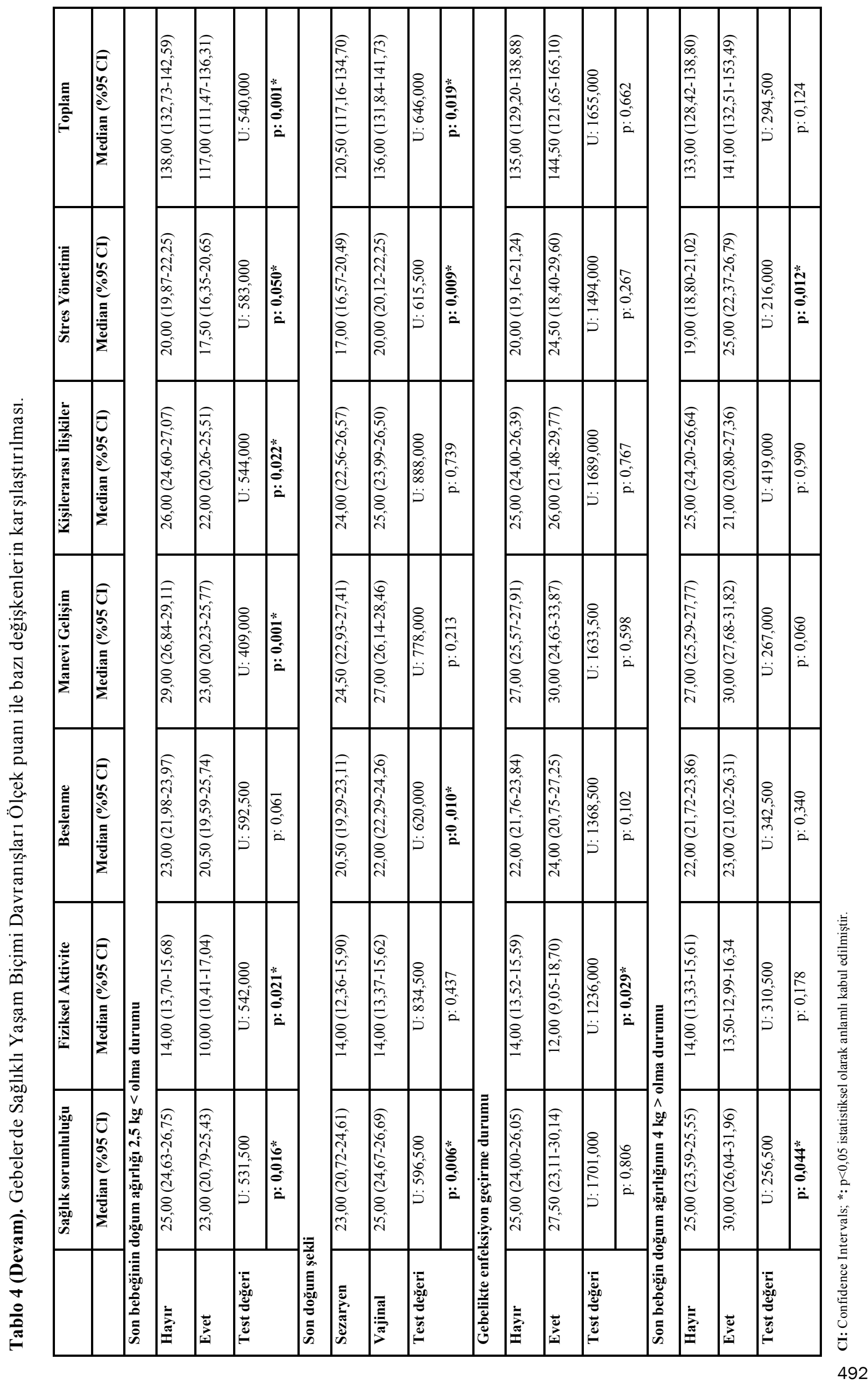

